\title{
Intestinal tuberculosis can be easily misdiagnosed as Crohn's disease
}

\section{Intestinal tüberküloz kolaylıkla Crohn hastalığı tanısı alabilir}

\author{
Pınar ÖKSÜZ ${ }^{1}$, Melek ÜNÇEL ${ }^{1}$, Hazal ALBAYRAK ${ }^{3}$, Özhan ÇETINDAĞ́ ${ }^{2}$, Özge KAYA ${ }^{1}$, Alp ÖZGÜZER ${ }^{1}$, \\ Gülden DINIIZ ${ }^{1}$
}

${ }^{I}$ Tepecik Ĕ̆itim ve Araştırma Hastanesi, Tıbbi Patoloji Ana Bilim Dalı, İzmir

${ }^{2}$ Tepecik Eğitim ve Araştırma Hastanesi, Genel Cerrahi Ana Bilim Dalı, İzmir

${ }^{3}$ Tepecik Eğitim ve Araştırma Hastanesi, Enfeksiyon Hastalıları Ana Bilim Dalı, İzmir

Dear Editor;

Tuberculosis (TB) is one of the most important infectious diseases worldwide. Recently its incidence has climbed in developed countries due to the increase in the number of refugees. The abdomen is involved in only one tenth of the patients with extrapulmonary tuberculosis which can pose a diagnostic challenge if not suspected beforehand. It is seen at an advanced age in Western countries while at younger age in developing countries. The prevalence of intestinal tuberculosis in both sexes is equal. Intestinal tuberculosis (ITB) constitutes only $1 \%$ of all patients with TB ${ }^{(1)}$. ITB may be caused by swallowing sputum in patients with primary pulmonary $\mathrm{TB}$, or by spread of microorganisms through hematogenous route in patients with other organ TB. Although ITB involves the entire gastrointestinal tract, most commonly ileocecal bowel is affected ${ }^{(1,2)}$. ITB has no specific signs or symptoms ${ }^{(2)}$. It can cause common symptoms, especially abdominal pain, weight loss, fever, fatigue, nausea, loss of appetite, vomiting, abdominal distension, and night sweats ${ }^{(3)}$.

A 40-year-old Syrian male patient arrived in emergency service with abdominal pain. His physical examination and imaging findings established the diagnosis of acute abdomen so he underwent an urgent surgery. Abdominal CT revealed evidence of multifocal lesions involving the ileocecal region with abdominal lymphadenopathy similar to those seen in Crohn's disease (CD) which was taken into consideration in differential diagnosis. Because of the presence of numerous adhesions, fistulas and microperforations, right hemicolectomy was performed. During the macroscopic evaluation of the specimen, increased thickness of the intestinal wall was observed, and intestinal mucosa appeared like a curbstone. Microscopically, edema, transmural inflammation, lymphoid hyperplasia and confluent granuloma containing caseous necrosis and giant cells were observed (Figure 1). In the first slide stained according to Ehrlich-Ziehl-Neelsen (EZN) method with autostainer, the background was pink because the fuchsine dye could not be removed sufficiently with acid and alcohol. Therefore any bacilli could not be seen in this slide and we repeated staining. There were a lot of acid- fast bacilli in the second slide stained by EZN method (Figure 2). With these findings, the case was diagnosed as intestinal tuberculosis. Microbiologically, the mycobacterium tuberculosis infection was also confirmed by culture. After diagnosis medical treatment of tuberculosis up to 12 months was initiated.

ITB causes diagnostic difficulties because it 


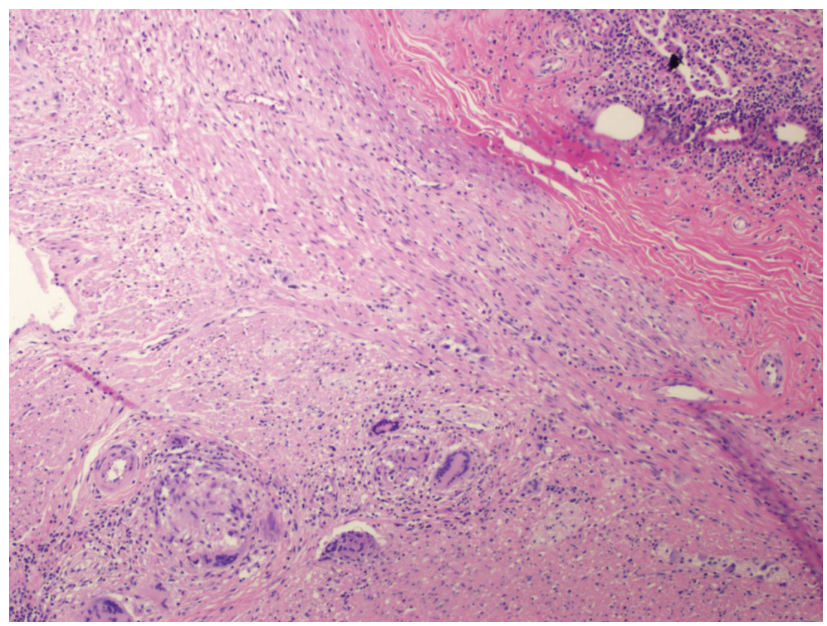

Figure 1. Serosal epithelioid cell granulomas with Langhan's giant cells (HEX40).

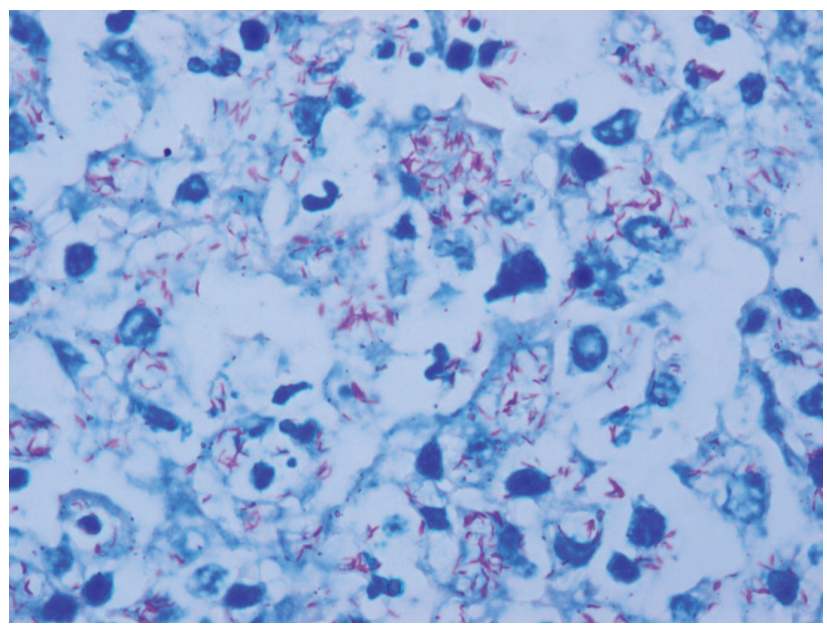

Figure 2. Note the plenty of pink bacilli stained by Ehrlich-ZiehlNeelsen stain (EZNX1000).

mimics $\mathrm{CD}$ and many abdominal disorders. In addition, there are no specific laboratory findings. The most common symptom is anemia associated with lymphocytosis, thrombocytosis, and elevation of erythrocyte sedimentation rate. Even in patients with common ulceration, fecal leukocytes or occult blood in feces could not be found. Mucosal ulceration, fistula, abscess, and granuloma are seen both in inflammatory bowel diseases and in ITB. Although granulomatous inflammation is specific for this disease, caseation necrosis may not always be seen ${ }^{(4)}$. None of the laboratory, radiologic and endoscopic methods can generally discriminate tuberculosis from inflammatory bowel disease. Microbiologic culture is the most important diagnostic method. The disadvantage of culture is that it yields results within 4-6 weeks ${ }^{(5)}$.

Herein, we want to remind you of the case of ITB, which caused difficulty in differential diagnosis by mimicking inflammatory bowel disease ${ }^{(6)}$. It is estimated that intestinal perforations occur in $1-15 \%$ of all patients with abdominal tuberculosis ${ }^{(5-7)}$, frequently requiring surgical intervention. Misdiagnosis followed by inadequate treatment may lead to adverse outcomes which require immunosuppressant treatment. Surgical treatment in tuberculosis may lead to reactivation of the disease that deteriorates the patient's condition and prolongs the treatment course. This patient was clinically misdiagnosed, and histopathological assessment was used for differential diagnosis.

In conclusion, it must not be forgotten that ITB can imitate the $\mathrm{CD}$ and pose difficulties in differential diagnosis Discrimination between these two diseases is challenging but important owing to variations in their management and dissemination potential of ITB under immunosuppression applied for $\mathrm{CD}^{(7)}$. TB should be absolutely ruled out in patients with inflammatory bowel disease, especially in patients with low socioeconomic conditions or immigrants coming from TB endemic countries. Again, as is seen in this case, it is imperative that TB-specific histopathological examinations of the specimens using EZN staining method should be standardized and controlled by experienced pathologists.

\section{REFERENCES}

1. Loh KW, Bassily R, Torresi J. Crohn's disease or tuberculosis? J Travel Med 2011;18:221-223.

https://doi.org/10.1111/j.1708-8305.2011.00509.x

2. Sharma R, Madhusudhan KS, Ahuja V. Intestinal tuberculosis versus crohn's disease: Clinical and radiological recommendations. Indian J Radiol Imaging 2016;26(2):161-72. https://doi.org/10.4103/0971-3026.184417

3. Huang X, Liao WD, Yu C, Tu Y, Pan XL, Chen YX, Lv NH, Zhu X. Differences in clinical features of Crohn's disease and intestinal tuberculosis. World $J$ Gastroenterol 2015;21(12):3650-6. https://doi.org/10.3748/wjg.v21.i12.3650

4. Doğan ÜB, Akın MS, Yalaki S, Demirtürk P.A case of tuberculous colitis mimicking Crohn's disease. Turk J Gastroenterol 2014;25(Suppl 1):260-1. 
https://doi.org/10.5152/tjg.2014.3727

5. Kim SH, Kim JW, Jeong JB, Lee KL, Kim BG, Choi YH. Differential diagnosis of Crohn's disease and intestinal tuberculosis in patients with spontaneous small-bowel perforation. Dig Surg 2014;31(2):151-6. https://doi.org/10.1159/000363066

6. Sood A, Midha V, Singh A. Differential diagnosis of Crohn's disease versus ileal tuberculosis. Curr Gastroenterol Rep
2014;16(11):418.

https://doi.org/10.1007/s11894-014-0418-9

7. Wei JP, Wu XY, Gao SY, Chen QY, Liu T, Liu G.Misdiagnosis and Mistherapy of Crohn's Disease as Intestinal Tuberculosis: Case Report and Literature Review. Medicine (Baltimore) 2016;95(1):e2436.

https://doi.org/10.1097/MD.0000000000002436 